\title{
Modelling of adsorption technologies for controlling indoor air quality
}

\author{
Carlos A. Grande ${ }^{1,2}$ (1)
}

Received: 30 July 2021 / Revised: 17 November 2021 / Accepted: 17 January 2022 / Published online: 27 January 2022

(C) The Author(s) 2022

\begin{abstract}
Technologies for control of indoor air quality are very important to ensure that health and comfort conditions are attained in closed environments. The indoor air quality market is fertile ground for adsorption technologies, both at larger industrial scale and for residential uses. The common strategy to design adsorption technologies considers constant inlet conditions, while for most indoor air control applications, the inlet conditions will change because of the partial removal of the contaminant. This work presents a generic modelling approach, where the adsorption technology is coupled with the indoor environment to be controlled. This approach enables a tailored and more accurate process design and additionally, it can also assist in the physical location of the removal unit and sensors to control its operation. Two different examples of application of this methodology are provided: control of $\mathrm{CO}_{2}$ in tightly closed environments and "peak shaving" of water vapor in bathrooms.
\end{abstract}

Keywords Process modelling $\cdot$ Indoor air quality $\cdot$ Adsorption $\cdot$ Carbon dioxide $\cdot$ Water

\section{Introduction}

Human beings rely on clean air for survival. The existence of pollutants in the air surrounding us is a problem that brings sensorial discomfort, can deteriorate health and in worse cases, carries life risks. Control of indoor air quality (IAQ) is a very important topic provided that humans are concentrated in closed environments for education, work, recreation, etc. $[1,2]$.

The type and quality of pollutants, their concentration and emission rate are extremely diverse and depends on many factors [3]. In households, the most common pollutants with health risks are volatile organic compounds [4], formaldehyde [5-7] and in some cases, ozone, radon, carbon monoxide and tobacco smoke [8]. Radon is the first cause of lung cancer among non-smokers [9]. The lack of control of relative humidity inside some areas of the house, particularly in the bathroom, can promote the formation of mold which produce allergens and irritants that are harmful to some people

Carlos A. Grande

carlos.grande@kaust.edu.sa

1 Division of Physical Sciences and Engineering, Advanced Membranes \& Porous Materials Center, King Abdullah University of Science and Technology, Thuwal 23955-6900, Kingdom of Saudi Arabia

2 SINTEF AS, Forskningsveien 1, 0373 Oslo, Norway
[10]. In households, the humidity generation is not constant and comes in peaks when events like shower or cloth drying happens. In commercial buildings the contaminants are the same, but in many cases there is some more specificity: i.e. there can be plenty of $\mathrm{CO}$ and $\mathrm{CO}_{2}$ in underground parking.

In underground parking of commercial and recreation buildings, important contaminants are carbon monoxide, nitrogen oxides and other products originated from transportation. In the other levels of such buildings, carbon dioxide can be problematic. Human beings exhale carbon dioxide and water in every breath $[11,12]$. Accumulation of carbon dioxide in closed environments has already been acknowledged and reported [13] [14]. The problem is increased in tight environments, like spaceships [15], Ebner et al. 2009; [16] or submarines [17], [18] where air evacuation is not an option. In those circumstances, without a $\mathrm{CO}_{2}$ removal device, the carbon dioxide exhaled can accumulate until a point where is dangerous to health. It has been previously reported that one astronaut emits around $42 \mathrm{~g}$ of $\mathrm{CO}_{2}$ per hour [19]. Accumulation of $\mathrm{CO}_{2}$ over $3 \%$ is already a health problem, while accumulation over $5 \%$ may possess life risks [20]. In such tight environments with a fixed crew, the generation of $\mathrm{CO}_{2}$ is continuous, and its amount can have variations depending on the activity level of the personnel. In buildings, the generation of $\mathrm{CO}_{2}$ depends on the amount of people present at a given fraction of time [21]. 
The legal requirements to comply healthy standards make the IAQ a multi-million market for different technologies for gas filtration and cleaning as well as for measuring devices. Estimating the market value is difficult because it depends very much on the items accounted: reported values range from 159 million USD [22] up to over 10 billion USD [23]. Major industrial players in the market are TSI, Lennox, Thermo Fisher Scientific, 3 M, Honeywell, Aeroqual, Teledyne, Trane, Carrier, Dyson, PPM, etc. The market share of large installations for industrial and commercial buildings is over $70 \%$ while the rest covers residential buildings.

To avoid accumulation of undesired substances in indoor environments, technologies for air cleaning or air filtering are energy efficient solutions. There are several technologies based on different physicochemical principles that can be used. Selective adsorption of targeted substances in porous adsorbents is an interest possibility [24, 25]. Adsorption processes are used for different polishing applications and are industrially acknowledged by their low energetic requirements. Moreover, adsorption units are known for presenting low maintenance requirements with adsorbents that are (or that can be tailored to be) environmentally friendly [26]. Utilization of adsorption technologies for air filtering has indeed shown that they can contribute to significant savings of energy when compared with standard ventilation systems [27] [21]. The adsorption equipment used in IAQ applications does not need to follow the traditional fixedbed columns arrangement,the desiccant rotating wheel for control of temperature and relative humidity in commercial buildings commercialized by Munters AS is a good example of technologies designed to operate with low pressure drop. Equipment can even be tailored to remove one or multiple components by using different layers of adsorbents [28].

The vast majority of the adsorption processes are designed with constant feed conditions [29, 30]. For designing an adsorption system for indoor air control there are two factors that should be considered and are, for simplicity, commonly ignored:

1. At least during some parts the operation, the rate of generation and the rate of adsorption will not be the same, so the rate of change of the component to be removed from the indoor volume should be accounted for, and

2. An optimized control system for the adsorption process should account for possible distributions of the contaminant in the indoor space, which implies that concentration should be considered as a function of the spatial location and an optimal location of the unit could be found.

An adsorption process can be designed without considering these two factors. However, in terms of process intensification, a more accurate design can result in a unit with a smaller size (and weight) and smaller power consumption. This work presents a mathematical model that solves the variation of given species in an indoor volume after integrating an adsorption technology for air purification. A distinctive feature of this model is that the inlet concentration of the component entering the fixed bed adsorption technology is changing with time as the component is being removed, or until a cyclic steady state is achieved.

The generic mathematical model is presented and used to simulate two different cases with different operation regimes: (a) continuous carbon dioxide removal from a closed environment (like a spaceship or a submarine) and (b) removal of water vapor peaks generated in bathrooms, termed here as "peak shaving". In this publication, the regeneration of the adsorbent is not considered because the main focus is to show how the concentration of the contaminant changes in the control volume under different circumstances. This work also shows how efficient model-driven design can assist in overcoming thermal effects produced from the fast adsorption of targeted components, both in terms of process design but also in customization of adsorbent shaping.

\section{Mathematical model}

Adsorption processes rely on the use of a selective material to remove one or more components from a fluid phase. After equilibrium between fluid and adsorbed phases is achieved, the adsorbent should be regenerated. For this reason, adsorption processes are transient and comprise different steps: adsorption, required regeneration steps and other steps to reestablish the system. When the adsorbent is packed in columns, the mathematical model of the columns is given by a set of partial differential equations with respect to time and at least one spatial dimension. While in certain circumstances only the mass balance can be used, the energy released by the adsorption phenomenon causes local temperature increase, and thus the energy balance should be solved simultaneously. Moreover, when the adsorption process is applied to a gas phase, the momentum equation $[31,32]$ or a simplification like the Ergun equation should be used to describe the pressure drop of the system caused by the bed(s) [33]. The system is solved with boundary conditions that change over time depending on the different steps used (adsorption, desorption, purge, etc.).

A simplified scheme of an adsorption process integrated in a closed environment to selectively remove one or more components is given in Fig. 1. Note that for simplicity, the volume of the adsorption process $\left(\mathrm{V}_{\mathrm{ads}}\right)$ is separated from the indoor volume $\left(\mathrm{V}_{\mathrm{b}}\right)$, but in most situations, the adsorption process will be placed inside the closed environment. It should also be noted that in this scheme, the necessary elements to regenerate the adsorbent are not considered. 


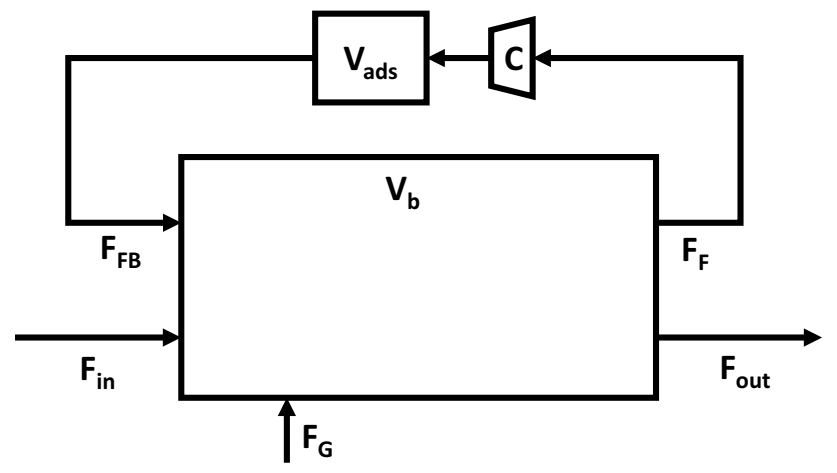

Fig. 1 a Scheme of the different inlet and outlet streams used for modelling the air purification of an indoor volume $\left(\mathrm{V}_{\mathrm{b}}\right)$ by an adsorption technology $\left(\mathrm{V}_{\mathrm{ads}}\right)$

The regeneration can be done by pressure reduction using a vacuum pump, or by temperature increase, either using a hot fluid or electricity [34]. The electricity can be used to directly heat the adsorbent or to power an electrical resistance that will heat the fluid used for regeneration. For certain operations (removal of VOCs), a thermal oxidation step may be more appropriate.

A mass balance for the component $i$ (to be removed) taken in the indoor volume is given by:

$F_{i n, i}+F_{F B, i}+F_{G, i}-\left(F_{\text {out }, i}+F_{F, i}\right)=\left.\frac{\partial n_{i}}{\partial t}\right|_{V_{b}}$

where $F_{i n, i}$ and $F_{\text {out }, i}$ are possible inlet and outlet streams to the system, respectively, $F_{F, i}$ is the stream that will be routed to the adsorption unit, $F_{F B, i}$ is the stream returning to the closed volume, $F_{G, i}$ is the flowrate of that component $i$ that is generated in the indoor volume and $\left(\partial n_{i} /\left.\partial t\right|_{V_{b}}\right)$ is the accumulation term in the indoor volume.

Using a similar rationale ("Inlets" - "Outlets" = "Accumulation"), the accumulation in the adsorption process $\left(\partial n_{i} /\left.\partial t\right|_{V_{a d s}}\right)$ is calculated by:

$F_{F, i}-F_{F B, i}=\left.\frac{\partial n_{i}}{\partial t}\right|_{V_{a d s}}$

For cases where the system is completely closed, $F_{\text {in }, i}=F_{\text {out }, i}=0$. In such cases, replacing Eq. (2) in Eq. (1) and rearranging, we obtain:

$\left.\frac{\partial n_{i}}{\partial t}\right|_{V_{b}}=F_{G, i}-\left.\frac{\partial n_{i}}{\partial t}\right|_{V_{a d s}}$

This equation can be used to depict different scenarios to describe how an adsorption technology can be used for indoor air purification:
1. This equation allows to establish the baseline scenario where only air recirculation and no adsorption technology is used and where $\partial n_{i} /\left.\partial t\right|_{V_{b}}=F_{G, i}$.

2. In circumstances where a continuous removal of a given component is targeted, the purification technology should be designed to avoid accumulation of such component in the indoor volume and the technology should be designed to achieve $\partial n_{i} /\left.\partial t\right|_{V_{a d s}}=F_{G, i}$. An example for such conditions is $\mathrm{CO}_{2}$ removal from tight environments, like spaceships and submarines.

3. Another possible application of an adsorption purification technology is to remove or "shave" peaks of a certain contaminant. If the technology starts after the generation ceased, then $\partial n_{i} /\left.\partial t\right|_{V_{b}}=-\partial n_{i} /\left.\partial t\right|_{V_{a d s}}$. This scenario is closer to the case of water removal from bathrooms during or after shower, or when painting locations with poor ventilation $[35,36]$. In this scenario, having a model where the indoor volume is directly coupled with the adsorption process is an advantage

To model an adsorption unit coupled to an indoor volume, different equations should be used to calculate each of the terms in Eqs. (1) and (2). The generation term in some cases is fixed or constant while in some cases is intermittent or changes with time [21]. The generation term is very important since it has a major role in sizing of the equipment. The accumulation terms (in the indoor volume and in the adsorption technology) should be calculated with independent equations describing the behaviour in the indoor volume (type of mixing, etc.) and also the type of adsorption technology (batch, fixed-bed, etc.). In this work, a perfectly stirred volume is used for describing the indoor volume where the contaminant concentration has to be controlled. A packed bed adsorption technology is used to remove such contaminant.

The mass balance for the perfectly mixed indoor volume is:

$\frac{\partial n_{i, b}}{\partial t}=\sum_{j=0}^{\text {inlets }} F_{i, j}-\sum_{k=0}^{\text {outlets }} F_{i, k}$

where $n_{i, b}$ is the number of moles of component $i$ in the indoor volume and $F_{i, j}$ and $F_{i, k}$ are the molar flowrate of component $i$ in the inlet and outlet streams to the indoor volume, respectively. The energy balance is given by:

$\frac{\partial n_{i, b} T_{b}}{\partial t}=\sum_{j=0}^{\text {inlets }} F_{i, j} T_{j}-\sum_{k=0}^{\text {outlets }} F_{i, k} T_{k}$

where $T_{b}$ is the temperature in the indoor volume and $T_{j}$ and $T_{k}$ are the temperature of inlet and outlet streams to the 
indoor volume, respectively. The component mass balance is given by:

$\frac{\partial n_{i, b} y_{i, b}}{\partial t}=\sum_{j=0}^{\text {inlets }} F_{i, j} y_{i, j}-\sum_{k=0}^{\text {outlets }} F_{i, k} y_{i, k}$

where $y_{i, b}$ is the molar fraction of component $i$ in the indoor volume and $y_{i, j}$ and $y_{i, k}$ are the molar fraction of component $i$ in the inlet and outlet streams to the indoor volume, respectively. Since the adsorption isotherms and the pressure drop require the pressure conditions, we should also use the ideal gas equation:

$y_{i, b} P_{b} V_{b}=n_{i, b} R T_{b}$

where $R$ is ideal gas constant and $P_{b}$ is the total pressure in the indoor volume. These equations allow the calculation of $n_{i, b}, y_{i, b}, T_{b}$ and $P_{b}$. These values are global variables that will be used for the calculations of the adsorption unit, as well as in the valves and the fan used to force the gas to pass through the fixed bed.

The mathematical model of the adsorption process has been previously used for very different applications and is given by a set of equations describing the mass, energy and momentum transfer in a packed bed [37, 38]. Diffusion is described as a bi-LDF (linear driving force) approach and the transient model is solved in only one spatial (axial) coordinate.

The mass balance in the gas phase is:

$$
\begin{aligned}
\varepsilon_{c} \frac{\partial C_{i}}{\partial t}+\frac{\partial\left(u C_{i}\right)}{\partial z}= & \varepsilon_{c} \frac{\partial}{\partial z}\left(D_{a x} C_{T} \frac{\partial y_{i}}{\partial z}\right) \\
& -\left(1-\varepsilon_{c}\right) \frac{a k_{m, i}}{\left(1+B i_{i} / 5\right)}\left(C_{i}-\bar{c}_{p, i}\right)
\end{aligned}
$$

where $C_{i}$ is the gas phase concentration of component $i, D_{a x}$ is the axial dispersion coefficient, $u$ is the superficial velocity, $y_{i}$ is the molar fraction of component $i, k_{m, i}$ is the film mass transfer resistance, $\bar{c}_{p, i}$ is the averaged concentration in the adsorbent particles, $C_{T}$ is the total gas concentration, $\varepsilon_{c}$ is the column void fraction, $a$ is the adsorbent specific area and $B_{i, i}$ is the Biot number.

A bi-disperse model for gas diffusion within the adsorbent is used. The mass balance in the macropores of the adsorbent particle is:

$\frac{\partial \bar{c}_{p, i}}{\partial t}=\frac{15 D_{p, i}}{r_{p}^{2}} \frac{B i_{i} / 5}{\left(B i_{i} / 5+1\right)}\left(c_{i}-\bar{c}_{p, i}\right)-\left(\frac{1-\varepsilon_{p}}{\varepsilon_{p}}\right) \rho_{s} \frac{\partial \overline{\overline{q_{i}}}}{\partial t}$

where $D_{p, i}$ is the macropore diffusivity, $r_{p}$ is the pellet radius, $\varepsilon_{p}$ is the pellet void fraction, $\rho_{s}$ is the solid adsorbent density and $\overline{\overline{q_{i}}}$ is the averaged adsorbed concentration of component $i$.

The mass balance in the micropores of the adsorbent is given by:

$\frac{\partial \overline{\overline{q_{i}}}}{\partial \mathrm{t}}=\frac{15 \mathrm{D}_{\mathrm{c}, \mathrm{i}}}{\mathrm{r}_{\mathrm{c}}^{2}}\left(q_{i}^{*}-\overline{\overline{q_{i}}}\right)$

where $D_{c, i}$ is the micropore diffusivity, $r_{c}$ is the crystal or micropore radius and $q_{i}^{*}$ is the amount adsorbed of component $i$ in equilibrium with the gas phase.

The Ergun equation is used to describe the pressure drop behavior along the column:

$\frac{\partial P}{\partial z}=-37.5 \frac{\mu_{G}\left(1-\varepsilon_{C}\right)^{2}}{\varepsilon_{C}^{3} r_{p}^{2}} u-0.875 \frac{\rho_{G}\left(1-\varepsilon_{C}\right)}{\varepsilon_{C}^{3} r_{p}} u \cdot|u|$

where $P$ is the total pressure, $\mu_{G}$ is the gas viscosity and $\rho_{G}$ is the density of the gas. If a honeycomb monolith or other ordered structures are used, other type of equations should be used to describe the pressure drop in the system. It should be noted that in systems where a fan or compressor passes the air through a bed, a good description of the pressure drop is very important.

Adsorption is an exothermic process and the energy released when adsorption takes place can contribute to increase the temperature of the adsorbent influencing its capacity to adsorb different components. In this work, different energy balances (for the gas phase, the solid adsorbent and the column wall) are used. The reason for using three different energy balances in a generic model is to be able to provide an accurate description of energy transfer provided that the adsorption process for control of indoor air quality may have very different sizes resulting in different heat transport mechanisms. Additionally, having other adsorbent shapes (honeycomb monoliths for example) may result in differences between the gas and the solid temperatures that should be considered to correctly quantify the amount adsorbed. The energy balance in the gas phase is:

$$
\begin{aligned}
\varepsilon_{C} C_{T} \hat{c}_{V g} \frac{\partial T_{g}}{\partial t}= & \frac{\partial}{\partial z}\left(\lambda \frac{\partial T_{g}}{\partial z}\right)-C_{T} \hat{c}_{P g} \frac{\partial\left(u T_{g}\right)}{\partial z} \\
& +\varepsilon_{C} R T_{g} \frac{\partial C_{T}}{\partial t}-\left(1-\varepsilon_{C}\right) a h_{f}\left(T_{g}-T_{S}\right) \\
& -\frac{2 h_{w}}{r_{W}}\left(T_{g}-T_{W}\right)
\end{aligned}
$$

where $T, T_{s}$ and $T_{W}$ symbolize the temperature in the gas phase, adsorbent and column wall, respectively, $\lambda$ is the heat axial dispersion coefficient, $\widehat{c}_{P g}$ and $\widehat{c}_{V g}$ are the gas molar specific heat at constant pressure and volume, respectively, $r_{W}$ is the internal radius of the cylindrical column and $h_{W}$ and 
$h_{f}$ as the film heat transfer coefficient between the gas phase and wall, and between gas phase and adsorbent, respectively. The energy balance in the solid phase is:

$$
\begin{aligned}
& {\left[\varepsilon_{P} \sum_{i=1}^{n c}\left(\bar{c}_{p, i} \hat{c}_{V g}\right)+\rho_{P} \sum_{i=1}^{n c}\left(\overline{\bar{q}}_{i} \hat{c}_{V a d s}\right)+\rho_{P} \hat{c}_{P S}\right]} \\
& \frac{\partial T_{S}}{\partial t}=\left[\varepsilon_{P} R T_{S} \sum_{i=1}^{n c}\left(\frac{\partial \bar{c}_{p, i} \hat{c}_{V g}}{\partial t}\right)+a h_{f}\left(T_{g}-T_{S}\right)\right] \\
& +\frac{\rho_{P}}{\left(1-\varepsilon_{C}\right)} \sum_{i=1}^{n c}\left(-\Delta H_{i} \frac{\partial \overline{\overline{q_{i}}}}{\partial t}\right)
\end{aligned}
$$

where $\widehat{c}_{\text {Vads }}$ is the molar specific heat at constant volume of adsorbed, $\widehat{c}_{P S}$ is the heat capacity coefficient of the material used to build the packed bed column and $\Delta H_{i}$ is the heat of adsorption of component $i$. The energy balance of the column is given by:

$\rho_{W} \hat{c}_{P_{W}} \frac{\partial T_{W}}{\partial t}=\frac{d_{W}}{e\left(d_{w}+e\right)} h_{w}\left(T-T_{W}\right)-\frac{U}{\left(d_{w}+e\right) \ln \left(\frac{d_{w}+e}{d_{w}}\right)}\left(T_{W}-T_{\infty}\right)$

where $\widehat{c}_{P w}$ is the specific heat of the column wall, $U$ is the heat transfer coefficient to the external environment with a temperature $T_{\infty}, \rho_{w}$ is the density of the material of the column wall, $d_{w}$ is the column diameter and $e$ is the thickness of the column wall.

The valves used in the system to communicate the different streams have simple open and close commands and the equation to describe them is:

$F_{\text {out }}=S_{p} X_{v} \Delta P$

where $F_{\text {out }}$ is the volumetric flowrate at the exit of the valve, $S_{p}$ is the stem position defined as 1 for an open valve and 0 for a closed valve, $X_{v}$ is the flow coefficient of the valve and $\Delta P$ is the pressure difference between inlet and outlet of the valve.

Since the compressor / fan used for the system depends strongly on the size and type of gases, in this initial work, a simple pressure driven flow was used where the pressure outlet $\left(P_{\text {out }}\right)$ is calculated by:

$P_{\text {out }}=G_{f} P_{\text {in }}$

where $P_{i n}$ is the inlet pressure and $G_{f}$ is the pressure gain coefficient.

To this set of equations, a system inlet and outlet were added to account for possible mass transfer coming and exiting the system, but that may not apply in all cases. The mathematical model of the system was solved in gPROMS (PSE Enterprise, UK). The equations in the adsorption column were solved with the orthogonal collocation of finite elements (OCFEM). A screenshot of the topology implemented in gPROMS is shown in the Supplementary Information together with the parameters needed to make the simulations for the two case studies presented in this work.

\section{Results and discussion}

\subsection{First example: continuous $\mathrm{CO}_{2}$ removal from closed environments}

In closed environments (like spaceships or submarines) where the air cannot be recycled, accumulation of carbon dioxide from respiration occurs. From an adsorption technology perspective, a higher concentration of $\mathrm{CO}_{2}$ results in higher loading in the adsorbent and thus a smaller size is required. However, since high $\mathrm{CO}_{2}$ concentration affects the health of the crew, a compromise should be found. While the international space station has a volume of approximately 1000 cubic meters for a crew of seven astronauts, other spaceships where $\mathrm{CO}_{2}$ removal technology is required, have a more compact design. For this work, the volume of gas to be treated was assumed to be 25 cubic meters for a crew of 2 astronauts. The two adsorption columns have a column radius and length of $0.15 \mathrm{~m}$ and are filled with zeolite 13X [39]. The rest of the details used in the simulations are listed in the Supplementary Information. Since this work only aims to demonstrate the modelling approach, water effects were not considered in the simulations. Indeed, for an improved $\mathrm{CO}_{2}$ removal under humid conditions, other type of materials can be used, like activated alumina [40] or some amine-loaded materials.

The molar fraction of $\mathrm{CO}_{2}$ in the closed volume is shown in Fig. 2a for the initial hours of operation (using two adsorption columns). The first result is obtained assuming that there is no $\mathrm{CO}_{2}$ cleaning technology. If no air treatment is applied, after $15 \mathrm{~h}(54,000 \mathrm{~s})$, the amount of $\mathrm{CO}_{2}$ increases linearly to over $3 \%$ which is dangerous for the health of the astronauts.

The $\mathrm{CO}_{2}$-removal technology employed can be operated in several ways. One possible operation method is that the unit is controlled by opening and closing valves while the fans are all time operating (termed here as valve control) so the gas is passing all time through one column. The columns are shifted when a certain gas molar fraction is obtained at the exit of the feed-processing column. The result of this approach leads to an initial longer utilization of the first column because the adsorbent starts adsorbing sequentially $\mathrm{CO}_{2}$ from low concentrations and heat effects are minimized. In this example, a $\mathrm{CO}_{2}$ molar fraction of $1.5 \%$ in the indoor (batch) volume was established as an arbitrary limit. It can be observed that the first column can process the air for $40,000 \mathrm{~s}$ while the $\mathrm{CO}_{2}$ concentration is 
Fig. 2 Effect of process operation in controlling the amount of $\mathrm{CO}_{2}$ in a closed environment: a molar fraction of $\mathrm{CO}_{2}$ in the volume to be purified; $\mathbf{b}$ temperature profile at the end $\left(\mathrm{L}_{\mathrm{c}}=0.15 \mathrm{~m}\right)$ of the adsorption processes and $\mathbf{c}$ amount of $\mathrm{CO}_{2}$ adsorbed at $\mathrm{L}_{\mathrm{c}}=0.15 \mathrm{~m}$ for each column
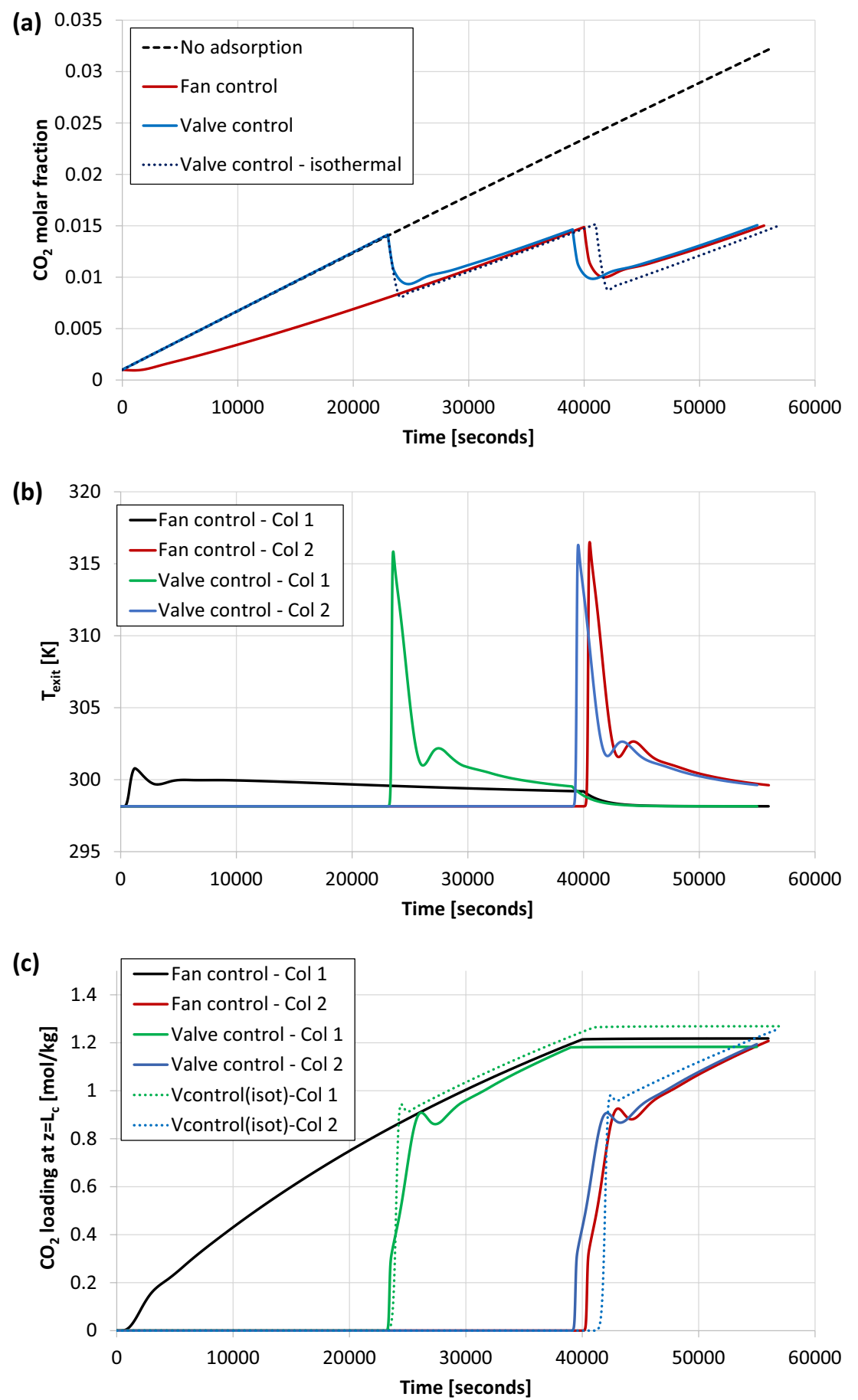

building up in the indoor (batch) volume. In cyclic operation where $\mathrm{CO}_{2}$ is already built up in the indoor volume, the adsorption column performance will be closer to the one observed with the second column, that can process air for $16,000 \mathrm{~s}$.

Alternatively, the technology can be started by turning on the compressors or fans only when the target molar fraction is achieved (termed here as fan control). This means that the initial period (23,000 s for this example), the gas will not be passing through the adsorption columns and it will only start passing through when $1.5 \% \mathrm{CO}_{2}$ is detected in the indoor (batch) volume.

When these results are plotted in the same graphic, it is possible to see that there are clear differences between these two approaches, caused only by having a different initialization procedure. When the air can pass through the first column 
from the initial moments when the contaminant concentration is very small, the temperature increase of the adsorbent bed is also very small since there is enough time to dissipate the heat generated. On the other side, when the gas enters the column already having $1.5 \% \mathrm{CO}_{2}$, there is a faster adsorption that results in a stronger thermal increase of almost $20 \mathrm{~K}$. The temperature at the exit of the adsorption columns for the cases described in this section are plotted in Fig. 2b. In the locations where the temperature increases, the local capacity of the adsorbent is smaller. Since the column cannot evacuate the heat fast enough, the adsorbent remains warmer for a longer period of time resulting in a net lower adsorption capacity. This is one of the reasons why the energy balance should be solved together with the mass balance; if the mathematical modelling considered the operation as isothermal, a better performance (longer column operation) could have been obtained as shown in Fig. 2a.

In Fig. 2c the amount of $\mathrm{CO}_{2}$ adsorbed at the end of the column is shown. As a consequence of the temperature oscillation, an initial peak is obtained in the analyzed cases. It should also be noted that once that the feed concentration of $\mathrm{CO}_{2}$ is changing at all time, the $\mathrm{CO}_{2}$ "plateau" normally obtained in breakthrough curves will not occur because of continuous generation. In that regard, when the molar fraction is around $1.5 \%$ the adsorbent has a capacity to adsorb around $1.2 \mathrm{~mol} / \mathrm{kg}$ of $\mathrm{CO}_{2}$. However, as the concentration decreases, the capacity also decreases and this is the reason for the first initial peak observed, both in the temperature and in the amount adsorbed.

In designing adsorption processes for air quality control, the standard approach is to use a fixed bed concentration and then "size" the unit. Integrating the adsorption process with the indoor volume allows an accurate sizing of the adsorption unit, but it can also help with having a more adapted process control because tailored sensors can be placed in the volume to be controlled. With the standard approach, the concentration changes within a given indoor (batch) volume are not considered and as can be seen from the results, the concentration of the component will be oscillating between the target value and one lower value that is proportional to the amount of $\mathrm{CO}_{2}$ adsorbed, to its diffusional resistances and also to the thermal management of the separation unit.

\subsection{Second example: peak shaving of water in bathrooms}

Another application where adsorption processes can have a significant impact in indoor quality control is to remove concentration peaks of a given contaminant or component. Common examples are VOCs after painting and water removal from a bathroom after a shower. Although water cannot be directly considered as a contaminant, it promotes the formation of mold in the more stagnant zones of the bathroom requiring periodic cleaning and repainting. The need for a dehumidifier strongly depends on the weather and housing temperature conditioning [41]. Commercial dehumidifiers do exist, but a technology based on adsorption can be less noisy, more compact and energy efficient. In places with mild temperatures and poor (or expensive) heating, the temperature of the bathroom can be $16-18{ }^{\circ} \mathrm{C}$ in winter at the moment to start the bath / shower. Depending on the design of the bathroom and the shower box, a shower with water at $37{ }^{\circ} \mathrm{C}$ will result in a sudden increase of the relative humidity of the bathroom from somewhere within the comfort zone (35-65\% relative humidity) to saturation. Longer shower time will also result in condensation of water in the bathroom walls and ceiling.

As an example, it is assumed that the bathroom volume is 10 cubic meters and an initial temperature of $291 \mathrm{~K}\left(18^{\circ} \mathrm{C}\right)$. The relative humidity at the beginning of the shower is fixed at $50 \%$. When the humidity in the bathroom achieves $70 \%$ (outside of the comfort zone), the adsorption unit starts operating. The shower lasts for $7 \mathrm{~min}$ and then generation of water vapour ceases, but the adsorption process keeps operating to return the humidity to the comfort zone (below $65 \%$ with a target in 50\%). In this work, the focus is only to see what happens in the bathroom and the regeneration of the material will not be studied.

For this initial work, a bed of silica gel (cheap adsorbent) was used and the properties of the material, adsorption isotherms and diffusional parameters are available in literature [42]. This example shows how the sizing of the equipment can be tuned for a more efficient water removal from this specific bathroom volume.

Without any water removal technology in the bathroom, the relative humidity attains $100 \%$ after $250 \mathrm{~s}(4.2 \mathrm{~min})$, assuming a rate of water vapor generation of $23 \mathrm{~L}$ per minute at $310 \mathrm{~K}$. After reaching $100 \%$ relative humidity and before water generation finished, liquid water will start condensing in colder surfaces (walls, ceiling, mirrors, etc.). The amount of water that enters the bathroom is $6.3 \mathrm{~mol}$ and assuming a silica gel capacity of $10 \mathrm{~mol} / \mathrm{kg}$, around $630 \mathrm{~g}$ of adsorbent will be needed to remove the entered amount of water. The adsorption equilibrium of water at 50\% RH (at $291 \mathrm{~K}$ ) is approx. $15 \mathrm{~mol} / \mathrm{kg}$, so assuming a loading of $10 \mathrm{~mol} / \mathrm{kg}$ should compensate for losses in overall column capacity due to axial dispersion, diffusion and thermal effects.

In Fig. 3, the relative humidity of the bathroom is shown for the base case where no water removal technology is used and for the case when a unit containing $630 \mathrm{~g}$ of silica gel is used. The length of the column is $\mathrm{L}=0.1 \mathrm{~m}$ and the porosity is $\varepsilon_{\mathrm{c}}=0.4$ (the rest of the values used for the simulations are reported in the Supplementary Information).

The adsorption technology only starts working when the relative humidity of the bathroom reaches $70 \%$ (step 1 in Fig. 3 while the water generation lasts until the end of step 2). As can be seen in Fig. 3, it takes a very long 
Fig. 3 a Relative humidity in the indoor volume with and without water removal, $\mathbf{b}$ amount adsorbed along the bed at three different times and $\mathbf{c}$ temperature along the bed at three different times
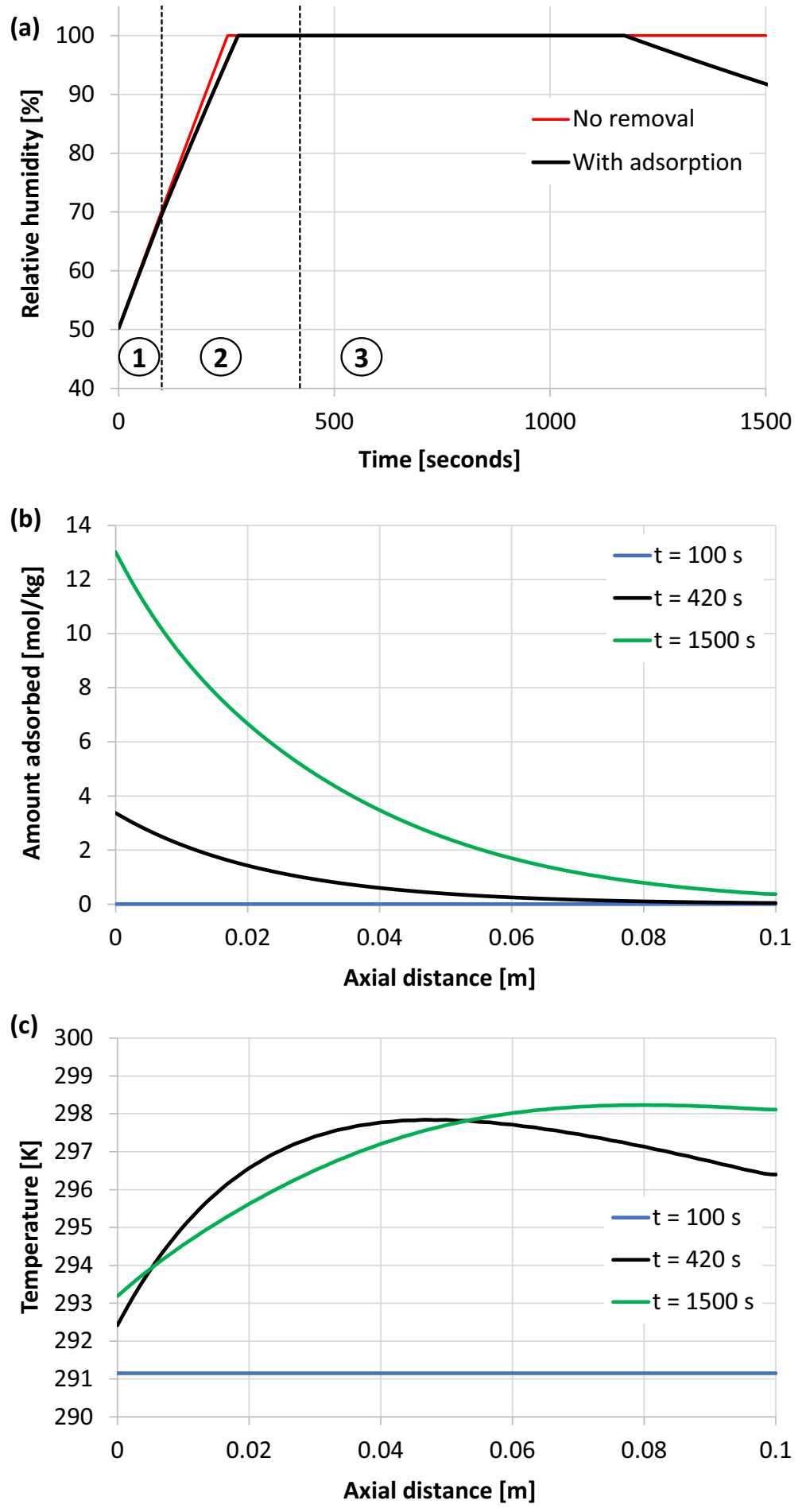

time until the relative humidity is controlled using this unit design. The amount of silica used efficiently is rather small and the main reasons are: (a) temperature increase due to adsorption, (b) rather low velocity through the bed and (c) diffusional effects. Increasing the gas velocity in the bed while keeping the same bed dimensions will result in additional power consumption and noise, which is not desired.
The thermal effects can only be reduced by adding some elements with higher heat capacity to the column [43].

Since the gas velocity through the adsorption unit is driven by pressure drop, a possibility to increase the gas velocity is to distribute the adsorbent in a shorter and thicker column [44]. If the column length is decreased by half and 
the radius of the column is increased by a factor of $\sqrt{2}$, the gas velocity can be increased from $0.23 \mathrm{~m} / \mathrm{s}$ to $0.34 \mathrm{~m} / \mathrm{s}$. The results of this simulation are shown in the Supplementary Information. Although the performance of the unit is significantly better, there is still condensation of water for a significant period and reestablishing the relative humidity at $50 \%$ takes long time. For this reason, a further reduction in the bed length to $0.025 \mathrm{~m}$ (doubling the original column radius to $0.099 \mathrm{~m}$ ) results in an increase in gas velocity to $0.40 \mathrm{~m} / \mathrm{s}$. The results of this simulation are shown in Fig. 4. Only by changing the column dimensions it is possible to make a much better adsorbent utilization. Although there is still a period where condensation is observed, this period
Fig. 4 a Relative humidity in the indoor volume with and without water removal with $\mathrm{L}_{\mathrm{c}}$ l $\mathrm{R}_{\mathrm{c}}=0.25$, $\mathbf{b}$ amount adsorbed along the bed at three different times and $\mathbf{c}$ temperature along the bed at three different times
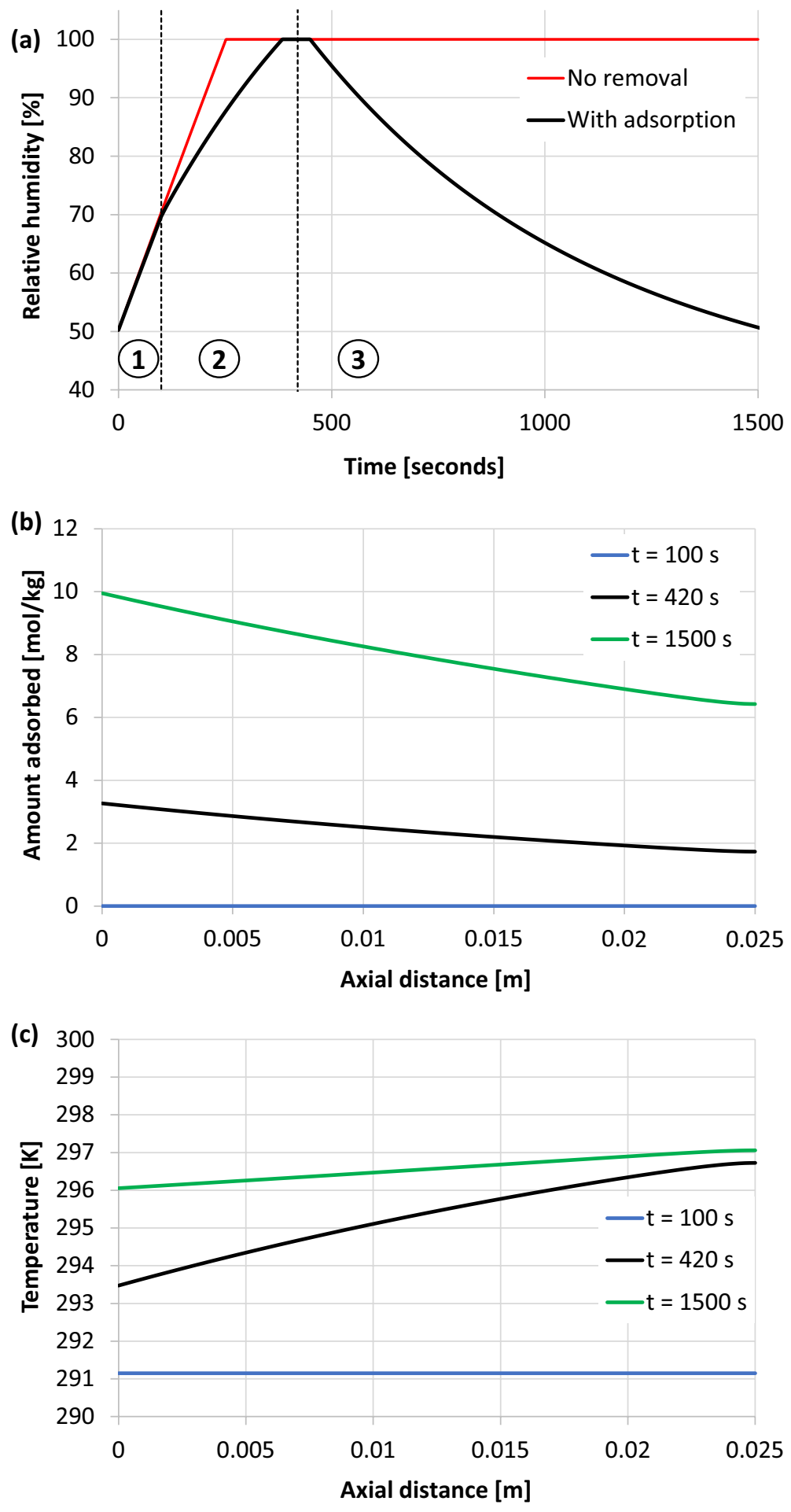
is very small and the relative humidity of the bathroom is reestablished after $20 \mathrm{~min}$ of operation. One of the important differences is that the temperature of the column is reduced because more gas enters the column and can contribute to cool down the adsorbent.

It has been shown that having a mathematical model with a good system description can help in improving the adsorbent utilization by changing the shape of the column. The design with a $L_{c} / R_{c}=2$ used initially results in a high pressure drop that limits the gas velocity inside the column and thus the column cannot be cooled down fast enough. The design with a $L_{c} / R_{c}=0.25$ ratio results in a faster adsorbent cooling promoted by a high gas velocity. A system with a radial feed is perhaps a more efficient and compact manner to implement low $L_{c} / R_{c}$ ratios. A process design that renders smaller beds should be favored. Such beds can be regenerated faster and at the same time can reduce capital cost. However, the size reduction will ultimately be defined by parameters like diffusion and dispersion and eventually thermal effects.

From the process point of view, another option that can be evaluated is how the shaping of the adsorbent impacts the process $[45,46]$. This evaluation starts by assuming that the properties of the adsorbent will be rather independent of the shaping (that should be verified experimentally). In the examples shown before, the diffusional limitations in the silica particles with a diameter of $2 \mathrm{~mm}$ are important, affecting the performance of the system. Decreasing the particle diameter to reduce diffusional resistances, will result in a larger pressure drop, so a tradeoff situation should be found. Although with this detailed model is also possible to find such tradeoff, the objective of this publication is only to demonstrate the features of a tailored model. The performance of the unit using particles with a diameter of $1 \mathrm{~mm}$ changes significantly as shown in Fig. 5. With smaller particles, the benefits of reduced diffusional limitations are more important than the loss of inlet gas velocity due to a larger pressure drop. The faster initial adsorption also results in a larger temperature excursion at the beginning of the operation, but the short length of the column contributes to a faster and efficient cooling. The cooling is not as efficient as in the results with the bigger particles (shown in Fig. 4) because the gas velocity is smaller. Indeed, it is observed
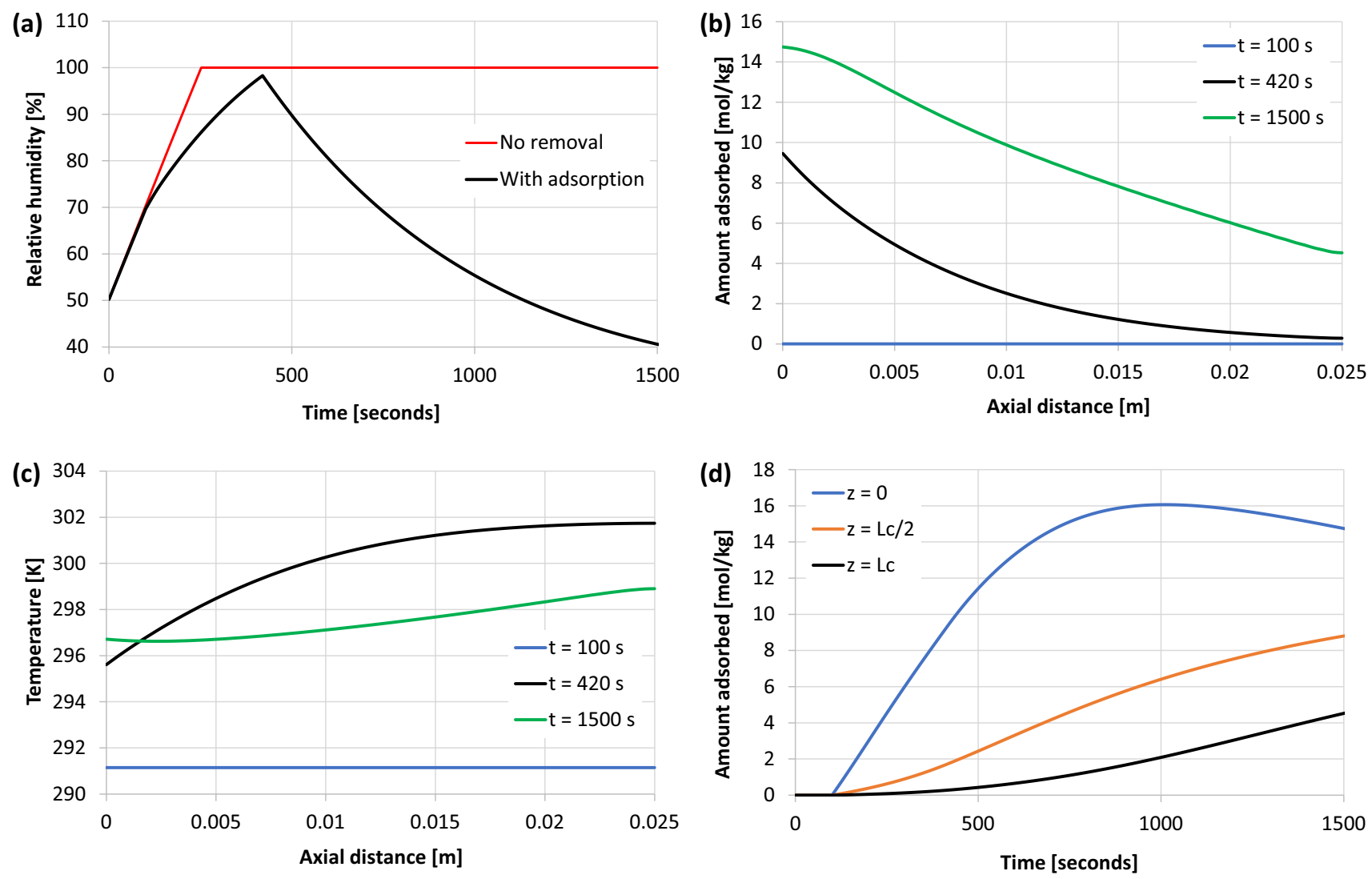

Fig. 5 a Relative humidity in the indoor volume with and without water removal with $\mathrm{L}_{\mathrm{c}} / \mathrm{R}_{\mathrm{c}}=0.25$ and silica particles with $1 \mathrm{~mm}$ diameter, $\mathbf{b}$ amount adsorbed along the bed at three different times, $\mathbf{c}$ tem-

perature along the bed at three different times and $\mathbf{d}$ evolution of the amount adsorbed in three different positions of the column 
that tailoring the adsorbent shape can be part of the strategy to achieve full process performance.

There are also two important things that should be mentioned. Controlling the process performance with the relative humidity can be slightly misleading when the temperature of the gas in the room changes. In Fig. 5, the operation for longer periods can take the relative humidity to values lower than the initial ones. However, the molar fraction in the gas phase only returns to the original place. The difference is in the saturation pressure because the temperature of the gas in the bathroom increases by almost $5 \mathrm{~K}$ degrees. Another important aspect shown in Fig. 5 is the evolution of the amount of water adsorbed in different positions of the column. If the system was modelled and designed with a constant water relative humidity of $50 \%$, the amount adsorbed of water could not exceed $15 \mathrm{~mol} / \mathrm{kg}$. The higher capacity of the adsorbent in the period where the amount of water vapor is between $50-100 \%$ relative humidity is retained and that is why a more accurate description of the equipment can be obtained.

\subsection{Future possibilities for adsorption technologies in IAQ markets}

In many countries, indoor air should comply regulated standards, at least in commercial and industrial buildings. Digitalization and advanced automation of diverse equipment are bringing advanced control of technologies to new platforms. Adsorption technologies have all possible advantages to be integrated into complex multi-purpose cleaning units with centralized control [47]. As mentioned before and as practiced in other adsorption applications, layering materials can be used to remove multiple components and this can be a factor for economical design of units in larger commercial buildings.

Large variety of materials has been reported in the last years; the metal-organic framework (MOF) community has a very powerful toolbox to tailor-design materials for different applications. Such utilization for advanced and miniaturized sensors that allow fast and reliable detection can be very powerful for advanced IAQ equipment control.

On a side note, it should be mentioned that the removal of any particular contaminants from commercial buildings is achieved by permanent air circulation. On the other side, the presence of human beings grants that the $\mathrm{CO}_{2}$ concentration in that air will be higher than in outdoor environments. Considering these factors (granted forced movement of air and higher $\mathrm{CO}_{2}$ concentration), $\mathrm{CO}_{2}$ capture from indoor environments should be more energy-efficient than $\mathrm{CO}_{2}$ capture from outdoors. Rotating wheel process was already suggested for $\mathrm{CO}_{2}$ removal from rather diluted flue gas streams and imposing a low pressure drop [48].
It is still unknown how will be the implementation of new IAQ technologies in a pos-pandemic scenario with remote working and enhanced online shopping of items. Although this should not affect the design of the technologies, this market context can drive the technological development towards residential applications, where adsorption can have benefits over other technologies.

\section{Conclusions}

This work presents a generic model of a packed bed adsorption process integrated in a finite volume representing an indoor volume where the concentration of a particular species (contaminant) should be controlled. The mathematical model of the system is used for two different examples of application: continuous removal of $\mathrm{CO}_{2}$ from closed environments and removal of peaks of water from bathrooms. The results obtained indicates that even for removal of small concentration of gases, the thermal effects can be important for designing these systems. Moreover, when the adsorption technology is driven by a fan and the flow of gas is regulated by the pressure drop along the column, the mathematical model can assist in achieving a good $\mathrm{L}_{\mathrm{c}} / \mathrm{R}_{\mathrm{c}}$ ratio that optimizes performance. Finally, it was also shown that assuming that the properties of the material are not changing with its shape, this mathematical model can also provide indications of the adequate shaping where a tradeoff between pressure drop and diffusion and/or thermal effects is achieved.

Supplementary Information The online version contains supplementary material available at https://doi.org/10.1007/s10450-022-00354-y.

Acknowledgements To the colleagues in SINTEF that contributed to my personal and professional development during ten years of my life. Part of this research was supported by the King Abdullah University of Science and Technology (KAUST).

Funding Open access funding provided by SINTEF AS.

Open Access This article is licensed under a Creative Commons Attribution 4.0 International License, which permits use, sharing, adaptation, distribution and reproduction in any medium or format, as long as you give appropriate credit to the original author(s) and the source, provide a link to the Creative Commons licence, and indicate if changes were made. The images or other third party material in this article are included in the article's Creative Commons licence, unless indicated otherwise in a credit line to the material. If material is not included in the article's Creative Commons licence and your intended use is not permitted by statutory regulation or exceeds the permitted use, you will need to obtain permission directly from the copyright holder. To view a copy of this licence, visit http://creativecommons.org/licenses/by/4.0/. 


\section{References}

1. Tham, K.W.T.: Indoor air quality and its effects on humansA review of challenges and developments in the last 30 years. Energy Buildings 130, 637-650 (2016)

2. Wolkoff, P.: Indoor air humidity, air quality, and health - An overview. Int. J. Hygiene Environ. Health 221, 379-390 (2018)

3. Zhang, Y.: Indoor Air quality Engineering. CRC Press, Boca Raton (2004)

4. Huang, S.-C., Chung, T.-W., Wu, H.-T.: Effect of molecular properties on adsorption of Six-carbon VOCs by activated carbon in a fixed adsorber. ACS Omega 6, 5825-5835 (2021)

5. Bian, Y., Wang, R., Wang, S., Yao, C., Ren, W., Chen, C., Zhang, L.: Metal-organic framework-based nanofiber filters for effective indoor air quality control. J. Mater. Chem. A. 6, 15807-15814 (2018)

6. Chen, Q., Liu, F., Mo, J.: Vertical macro-channel modification of a flexible adsorption board with in-situ thermal regeneration for indoor gas purification to increase effective adsorption capacity. Environ. Research 192, 110218 (2021)

7. Lu, Y., Wang, D., Ma, C., Yang, H.: The effect of activated carbon adsorption on the photocatalytic removal of formaldehyde. Building Environ. 45, 615-621 (2010)

8. USEPA. Indoor pollutants and sources. Available at: https://www. epa.gov/indoor-air-quality-iaq/indoor-pollutants-and-sources. Accessed 03/05/2021.

9. WHO Regional office for Europe: Indoor air quality: RadonReport on a WHO working group. J. Environ. Radioact. 8, 73-91 (1988). https://doi.org/10.1016/0265-931X(88)90015-X

10. USEPA. Mold and health. Available online: https://www.epa.gov/ mold/mold-and-health Accessed: 03/05/2021.

11. Tang, X., de l'Aulnoit, S.H., Buelow, M.T., Slack, J., Singer, B. C., Destaillats, H.: Performance of a $\mathrm{CO} 2$ sorbent for indoor air cleaning applications: effects of environmental conditions, sorbent ageing, and adsorption of co-occurring formaldehyde. Indoor Air 30, 1283-1295 (2020)

12. Zhao, R., Liu, L., Zhao, L., Deng, S., Li, S., Zhang, Y., Li, H.: Thermodynamic exploration of temperature vacuum swing adsorption for direct air capture of carbon dioxide in buildings. Energy Conv. Manag. 183, 418-426 (2019)

13. Griffiths, $\mathrm{M} .:$ Eftekhari, $\mathrm{M}$, : Control of $\mathrm{CO}_{2}$ in a naturally ventilated classroom. Energy Build. 40, 556-560 (2008)

14. Rajan, P.E., Krishnamurthy, A., Morrison, G., Rezaei, F.: Advanced buffer materials for indoor air $\mathrm{CO} 2$ control in commercial buildings. Indoor Air 27, 1213-1223 (2017)

15. Rosen, M.S., Mulloth, L.M., Aff;eck, D.L., Wang, Y., LeVan, M.D,: Development and testing of a temperature swing adsorption compressor for carbon dioxide in closed-loop air revitalization systems. SAE Technical Paper (2005). https://doi.org/10.4271/ 2005-01-2941

16. Mattox, E.M., Knox, J.C., Bardot, D.M.: Carbon dioxide removal system for closed loop atmosphere revitalization, candidate sorbents screening and test results. Acta Astonautica 86, 39-46 (2013)

17. Carey, A., Gomezplata, A., Sarich, A.: An overview into submarine $\mathrm{CO}_{2}$ scrubber development. Ocean Engng 10, 227-233 (1983)

18. Molecular website. Carbon dioxide self powered absorber CASPA. Available at: https://www.molecularproducts.com/produ cts/caspa. Assessed on 03/05/2021.

19. NASA: Jet propulsion laboratory. The air up there. Available at: https://www.jpl.nasa.gov/edu/pdfs/airupthere.pdf . Assessed on 06/05/2021.

20. FSIS Environmental. Carbon dioxide health hazard information datasheet. Available at: https://www.fsis.usda.gov/sites/defau
1t/files/media_file/2020-08/Carbon-Dioxide.pdf. Assessed on 06/05/2021.

21. Sinha, A., Thakkar, H., Rezaei, F., Kawayiri, Y., Realff, M.: Direct Air Capture of $\mathrm{CO} 2$ in enclosed environments: design under uncertainty and techno-economic analysis. Computer Aided Chemical Engineering 44, 2179-2184 (2018)

22. MarketStudyReport. Global Indoor Air Quality market 2020 by company, regions, type and application, forecast to 2025. Available at: https://www.marketstudyreport.com/reports/global-indoorair-quality-market-2020-by-company-regions-type-and-appli cation-forecast-to-2025 Accessed: 17/11/2021.

23. GrandViewResearch. Indoor Air Purification market analysis by product (dust collectors \& vacuums, fume \& smoke collectors, mist eliminators), by technology, by application, and segment forecasts to 2024. Available at: https://www.grandviewresearch. com/industry-analysis/indoor-air-purification-market Accessed: $17 / 11 / 2021$.

24. Luengas, A., Barona, A., Hort, C., Gallastegui, G., Platel, V., Elias, A.: A review of indoor air treatment technologies. Rev. Environ. Sci. Biotechnol. 14, 499-522 (2015)

25. Yue, X., Ma, N.L., Sonne, C., Guan, R., Lam, S.S., Le, Q.V., Chen, X., Yang, Y., Gu, H., Rinklebe, J., Peng, W.: Mitigation of indoor air pollution: a review of recent advances in adsorption materials and catalytic oxidation. J. Hazard. Mater. 405, 124138 (2021)

26. Grande, C.A., Blom, R., Spjelkavik, A., Moreau, V., Payet, J.: Life-cycle assessment as a tool for eco-design of metal-organic frameworks (MOFs). Sust. Mater. Tech. 14, 11-18 (2017). https:// doi.org/10.1016/j.susmat.2017.10.002

27. Zhang, Y., Mo, J., Li, Y., Sundell, J., Wargocki, P., Zhang, J., Little, J.C., Corsi, R., Deng, Q., Leung, M.H.K., Fang, L., Chen, W., $\mathrm{Li}, \mathrm{J} .$, Sun, Y.: Can commonly-used fan-driven air cleaning technologies improve indoor air quality? A literature review Atmospheric Environ. 45, 4329-4343 (2011). https://doi.org/10.1016/j. atmosenv.2011.05.041

28. Tyndall, D.W., Golden, T.C., Farris, T.S., Taylor, F.W., Furlan, W.R., Rabasco, J.J. Apparatus and process for air cleaning. US Patent, 7381244 (2008).

29. Da Silva, C.F., Stefanowski, B., Maskell, D., Ormondroyd, G.A., Ansell, M.P., Dengel, A.C., Ball, R.J.: Improvement of indoor air quality by MDF panels containing walnut shells. Building Environ. 123, 427-436 (2017)

30. Popescu, R.S., Blondeau, P., Jouandon, E., Costes, J.C., Fanlo, J.L.: Elemental modelling of adsorption filter efficiency for indoor air quality applications. Building Environ. 66, 11-22 (2013)

31. Hsu, C.-N., Tsai, Y.-L.: Experimental measurement and computational simulation analysis of indoor air quality in office - Integration of voltage dust collection device and energy recovery ventilator. Sensors Mater. 32, 4299-4321 (2020)

32. Roegiers, J., Denys, S.: CFD-modelling of activated carbon filters for indoor air purification. Chem. Eng. J. 365, 80-87 (2019)

33. Sereno, C., Rodrigues, A.E.: Can Steady-State Momentum Equations Be Used in Modelling Pressurization of adsorption Beds? Gas Sep. Purif. 3, 167-174 (1993)

34. Lee, T.S., Cho, J.H., Chi, S.H.: Carbon dioxide removal using carbon monolith as electric swing adsorption to improve indoor air quality. Building Environ. 92, 209-221 (2015)

35. Jeon, J., Park, J.H., Wi, S., Yun, B.Y., Kim, T., Kim, S.: Field study on the improvement of indoor air quality with toluene adsorption finishing materials in an urban residential apartment. Environ. Pollut. 261, 1141 (2020)

36. Lorimier, C., Subrenat, A., Le Coq, L., Le Cloirec, P.: Adsorption of toluene onto activated carbon fibre cloths and felts: application to indoor air treatment. Environmental Technol. 26, 1217-1230 (2005) 
37. Da Silva, F.A., Silva, J.A., Rodrigues, A.E.: A General Package for the Simulation of Cyclic Adsorption Processes. Adsorption 5, 229-244 (1999)

38. Rocha, L.A.M., Andreassen, K.A., Grande, C.A.: Separation of $\mathrm{CO} 2 / \mathrm{CH} 4$ using carbon molecular sieve (CMS) at low and high pressure. Chem. Eng. Sci. 164, 148-157 (2017). https://doi.org/ 10.1016/j.ces.2017.01.071

39. Cavenati, S., Grande, C.A., Rodrigues, A.E.: Adsorption equilibrium of methane, carbon dioxide and nitrogen on zeolite $13 \mathrm{X}$ at high pressures. J. Chem. Eng. Data 49, 1095-1101 (2004). https:// doi.org/10.1021/je0498917

40. Li, G., Xiao, P., Webley, P.: Binary Adsorption Equilibrium of Carbon Dioxide and Water Vapor on Activated Alumina. Langmuir 25(18), 10666-10675 (2009). https://doi.org/10.1021/la901 $107 \mathrm{~s}$

41. Nakabayashi, S., Nagano, K., Nakamura, M., Togawa, J., Kurokawa, A.: Improvement of water vapor adsorption ability of natural mesoporous material by impregnating with chloride salts for development of a new dessicant filter. Adsorption 17, 675-686 (2011)

42. Grande, C.A., Morence, D.G.B., Bouzga, A.M., Andreassen, K.A.: Silica gel as a selective adsorbent for biogas drying and upgrading. Ind. Eng. Chem. Res. 59, 10142-10149 (2020). https:// doi.org/10.1021/acs.iecr.0c00949

43. Yang, R.T.: Gas separation by adsorption processes. Butterworths, Boston (1986)
44. Yang, X., Wang, H., Chen, J., Li, Z., Liu, Y., Zhang, C., Xing, Y.: Two-dimensional modelling of pressure swing adsorption (PSA) oxygen generator with radial-flow adsorbed. Appl. Sci. 9, 1153 (2019)

45. Lawson, S., Griffin, C., Rapp, K., Rownaghi, A.A., Rezaei, F.: Amine-Functionalized MIL-101 monoliths for CO2 removal from enclosed environments. Energy Fuels 33(3), 2399-2407 (2019)

46. Thakkar, H., Eastman, S., Hajari, A., Rownaghi, A.A., Knox, J.C., Rezaei, F.: 3D-printed zeolite monoliths for $\mathrm{CO} 2$ removal from enclosed environments. ACS Appl. Mater. Interfaces 8, 2775327761 (2016)

47. Pham, H.M., Morgan, S.K., Butler, B.R. Humidifier control system and methods. US Patent 10760804 (2020).

48. Herraiz, L., Palfi, E., Sanchez Fernandez, E., Lucquiaud, M.: Rotary adsorption: selective recycling of $\mathrm{CO}_{2}$ in combined cycle gas turbine power plants. Front. Energy Res. 8, 482708 (2020). https://doi.org/10.3389/fenrg.2020.482708

Publisher's Note Springer Nature remains neutral with regard to jurisdictional claims in published maps and institutional affiliations. 